\title{
The Effect of Oil Prices on Stock Prices: Fresh Evidence from Asymmetric Causality Tests
}

\author{
Abdulnasser Hatemi-J \\ UAE University \\ E-mail: AHatemi@uaeu.ac.ae \\ Abdulrahman Al-Shayeb \\ UAE University \\ E-mail: a.alshayeb@uaeu.ac.ae \\ Eduardo Roca \\ Department of Accounting, Finance and Economics, \\ Griffith University \\ Email: E.Roca@griffith.edu.au
}

\begin{abstract}
This article investigates the causal impact of oil prices on stock prices in each G7 market as well as in the world market. An asymmetric causality test is used for this purpose. Since the underlying data appears to be non-normal with time-varying volatility, we use bootstrap simulations with leverage adjustments in order to produce more reliable critical values than the asymptotic ones. Based on symmetric causality tests, we find no causal effect of oil prices on the stock prices of the world market or any of the G7 countries. However, when we apply an asymmetric causality test, we find that increasing oil prices cause stock prices to rise in the world, the US and Japan while decreasing oil prices cause stock prices to fall in Germany. This may imply that the world, US and Japanese stock markets consider increases in oil prices as an indicator of good news as this may mean that there is an increase in oil demand due to an expected growth in the economy while the German stock market treats decreasing oil prices as a signal of an expected contraction in the economy.
\end{abstract}

Keywords: Oil Prices, Stock Markets, G7, Asymmetric Causality

JEL Classification: G15, C32 


\section{Introduction}

Fossil oil is still a major source of energy in any modern economy. This is expected to be the case for a foreseeable future. Hence, oil prices are usually one of the main factors behind fluctuations in many markets including financial markets and in particular stock

markets. There is now a huge body of literature on the effect of oil prices on the economy for both developed and emerging countries. The bulk of these studies show that indeed oil price shocks affect the economy significantly (Hamilton, 2003; Cunado and Perez de Garcia, 2005; El-Sharif et. al., 2005; Lardic and Mignon, 2008; Gronwald, 2008; Cologni and Manera, 2008; Kilian, 2008; Narayan and Narayan, 2010; Arouri and Rault, 2012) However, there are still a relatively small number of studies on the effect of oil prices on stock prices. Furthermore, these studies yield mixed results with some showing a significant relationship between these two variables while others do not. The results vary depending on the countries studied and time period covered. Thus, there seems to be no general consensus yet on the effect of oil prices on stock prices.

We address this important gap in the literature. In this study, we examine the impact of oil prices on stock market prices in each of the G7 countries and on the world as a whole through the use of a newly developed technique that considers for asymmetry in the relationship between variables - that of Hatemi-J (2012). It is well-known in the literature that asymmetric impacts prevail in many markets especially in financial ones (Black, 1976; Christie, 1982; French, et. al., 1987; Nelson, 1991 and Schwert, 1990, among others). Bad news affects stock prices more than good news. Campbell and Hentschel (1992) argue that the mere arrival of information itself can bring about this asymmetry. News, per se, because of its being unexpected, can increase share price volatility but when it is bad, the effect is magnified. A change in oil prices can be regarded by stock markets as either good news or bad news; hence, stock markets can have an asymmetric response to the change in oil price. An increase in oil prices could be perceived as bad news by stock markets in the sense that it can negatively affect the economy while the opposite could be regarded as good news as it can have a positive effect on the economy. 
However, it could also be that stock markets consider an increase (decrease) in oil prices as good (bad) news as they may regard it as an indication of an increase in demand for oil which signifies a growth (contraction) in the economy. Whatever the case is, what is clear is that a change in oil prices could be regarded by stock markets as representing either good news or bad news, and hence, there could be asymmetry in the relationship between oil prices and stock prices under conditions of bad news and good news. Thus, it is important to conduct the analysis of the relationship between oil prices and stock prices under different conditions - good news conditions as well as bad news conditions.

In order to do this, we use a newly developed asymmetric causality test, that of Hatemi-J (2012), which is discussed in detail in Section 3. The existing articles that try to allow for some form of non-linearity or asymmetry are usually based on the Markov chains, thresholds or indicator variables. However, these approaches are basically based on the same model without totally separating the positive shocks from the negative ones. The asymmetric causality test that we implement in this article can overcome this potential shortcoming. Unlike previous methods, the current asymmetric causality test provides the possibility to investigate the impact of positive changes of one variable on positive changes of another variable as wells as the impact of negative changes of one variable on negative changes of another variable or any other combination that one might be interested in.

Another pertinent issue within this context is the fact that financial data is not normally distributed and volatility is usually not constant but time-varying (French, et al, 1987; Campbell and Hentschel, 1992; Nelson, 1991). In such circumstances, tests for causality based on asymptotic critical values perform poorly. In order to remedy this potential shortcoming, we make use of bootstrap simulations with leverage adjustments to produce critical values that are more precise. These critical values are produced for symmetric Granger causality test as well as for asymmetric causality tests. 
To our knowledge, there is no study yet on the relationship between oil prices and stock prices which has utilized an asymmetric causality approach despite being wellestablished that in markets, the effect of financial variables is usually asymmetric. Our study therefore will provide fresh evidence on this issue based on this newly developed methodology.

The rest of the paper is organized as the following. Section 2 provides literature review. Section 3 presents the econometric approach. Section 4 discusses the empirical findings and the last sections offers concluding remarks.

\section{Literature Review}

Ample of research studies have examined the relationship between oil prices and macroeconomic variables; such as inflation, employment, exchange rates and growth rates with an inverse relationship (e.g. Burbidge and Harrison, 1984; Cunado and Perez, 2003, 2005; Engemen et al., 2011; Hamilton, 1983, 2003, 2011; Kilian 2008,2009; Mork, 1989; Mok et al. 1994). For example, Hamilton (1983) and (2011) show that seven out

of eight and ten out of eleven, respectively, postwar US recessions had been preceded by a rise in oil prices, as a result of finding negative and significant correlation between oil price increases and output. Sardorsky (1999), Park and Ratti (2008) and Apergis and Miller (2009) find that oil prices movements affect economic conditions such as growth, inflation rates and interest rates. Basher and Sadorsky (2006) suggest that the cost of nonoil production inputs are mostly absorbed by the companies and depress companies' profits and dividend which in turn affect stock returns.

The impact of oil prices on stock market returns also has been documented in the economics literature with mixed evidence suggested. The first strand documents a negative impact of oil price movements on stock returns (e.g. Kaul and Seyhun, 1990; Jones and Kaul,1996; Sadorsky; 1999; Papapetrous, 2001; Hong et al., 2002; Hammoudeh and Li, 2008; Ghouri, 2006; Basher and Sadorsky, 2006; Hammoudeh and Choic, 2007; Driesprong et al., 2008; Nandha and Faff, 2008; O’Neil et al., 2008; Park 
and Ratti, 2008). For instance, Jones and Kaul (1996), using a standard cash flow valuation model, report a negative correlation between oil prices and stock prices in four countries: US, Canada, Japan and the UK. In another study, Sadorsky (1999), using monthly data for the period 1947 to 1996, finds that the volatility of oil prices negatively affected US stock market movements and any increase in oil prices causes negative shocks to US stock prices. Furthermore, Papapetrous (2001) reached the same conclusion of a negative impact on stock prices as oil prices negatively affect output as well as employment growth. O’Neil et al. (2008) and Park and Ratti (2008), report a significant negative impact of oil price shocks on stock prices for an extended sample of 13 developed market.

Other studies, on the other hand, suggest a positive impact of oil prices on stock market returns. Most recently, Chiang et al (2015) documented comprehensively a positive impact of oil prices on the returns of different portfolios of stocks in the US market after controlling for well-known risk factors that affect returns. Sadorsky, (2001) report a significant positive relationship between oil prices and stock return coming from oil and gas firms in Canada, using a multifactor market model. El-Sharif et al. (2005) find a significant positive association between oil prices and oil-related stocks, listed on London Stock Exchange), using a sector-based analysis. Studying the European and US stocks for the period June 2000 to July 2011, Reboredo and Rivera-Castro (2014), as one of their main findings, find that oil and gas companies were positively affected by oil price movements as an exception for the independent effect between the two. Other studies that report positive effects of oil prices on stock returns are those of Faff and Brailford, 1999; Sadorsky, 2001; El-Sharif et al. 2005; Gogineni, 2007; Yurtsever and Zahor, 2007; Arouri and Rault, 2012)

The other strand of studies documents an independent relationship between oil prices and market returns, (Chen et al. 1986; Huang et al., 1996; Hennriques and Sadorsky, 2008; Apergis and Miller; 2009, Reboredo and Rivera-Castro; 2014). Huang et al. (1996) find that oil stock futures returns are not correlated to stock returns. Güntner (2013), using 
monthly data from 1974 to 2011 for 6 OECD countries, reports stock returns in any selected economies are not affected by oil supply unexpected fluctuations. Similarly, Reboredo and Rivera-Castro (2014), find that oil price changes had no impact on stock market returns at both the aggregate and sectorial levels in the pre-crisis period with exceptions with exception of oil and company stocks.

It is very important to a number of those studies that found evidence of a significant relationship between stock prices and oil prices point out that the relationship is nonlinear. For example, among others, the study by Ajmi et al (2014) which investigated this relationship based on an asymmetric causality test and in the context of the Middle East and North African region over the period 2007 to 2012 yielded the same finding. Utilising copula models, Naifar and Al Dohaiman (2013) and Zhu et al. (2014) also found significant asymmetric linkage between the crude oil and stock markets in the GCC and Asia-Pacific regions, respectively. Further evidence has also been provided by the study of Jawadi et al (2010) which found a non-linear long run relationship between oil prices and stock prices based on the use of switching transition error correction models. With the use also non-linear cointegration techniques, Maghyereh et al (2007), in their study relating to the five member countries (Bahrain, Kuwait, Oman, Saudi Arabia, and the United Arab Emirates) of the Gulf Cooperation Council arrived at the same conclusion. Jammazi and Aloui (2010), using a combined wavelet analysis and Markov Switching Vector Autoregressive (MS-VAR) approach, likewise found an asymmetric relationship between oil prices and stock returns depending on the phases of the markets.

The same picture emerges as regards the link between these two variables in the case of the G7 countries. There are only a handful of studies which have investigated the link between oil prices and stock prices. These studies have also yielded mixed results. One of these studies is that of Christensen 2011. This study also included Norway. It applies mostly the same models as those of the papers by Sadorsky (1999), Park and Ratti (2008), Cong et al. (2008) and Ono (2011) which utilise a vector autoregression (VAR) model for the period between 1986 and 2010, where the impulse response and the variance decomposition are estimated. The VAR model contains four variables; interest 
rate, oil price, industry production and real stock return. The study finds little evidence of a linear impact oil price shocks; however, it does find significant non-linear effect. The results of the variance decomposition indicate that an increase in oil price have a more powerful impact on the net oil importing countries and Norway, while for Canada and Japan, the impact of a decrease in oil price has a more powerful effect. In contrast to these results, no evidence is found of an asymmetric impact of oil price shocks on real stock returns of the G-7 and Norway.

Applying sector stock prices and oil prices in 1991:01-2009:05 from the G7 countries, Lee et al (2012) find that oil price shocks do not significantly impact the composite index in each country. However, stock price changes in Germany, the UK and the US were found to lead oil price changes. As for the interaction between oil price changes and sector stock price changes, we find short-run negative causal relationships: 4 of 7 sector index returns were impacted by oil price changes in Germany, 2 in the US and 1 in France. In particular, stock returns of information technology and consumer staples sectors were found to be impacted most by oil price shocks, followed by financial, utilities and transportation sectors. In terms of causality from sector stock price changes to oil price changes, they found that stock price changes lead oil price changes in 8 of 9 sectors in Germany, most in the G7 countries followed by the UK, Italy, France, Canada and the US. No such causal relationship, however, is found for Japan. With respect to specific sectors, stock price changes in consumer staples and materials sectors were impacted most significantly by oil price changes followed by transportation, financial, energy, health care, industrials, utilities, information technology and telecommunication sectors with the exception of consumer discretionary sector. In addition, short term stock price changes are found to lead positively oil price changes.

Finally, there is also the article by Lee and Zeng (2011). This paper examines the impact of changes in real oil prices on the real stock returns of G7 countries. They find the responses of stock markets to oil price shocks to be diverse among G7 countries 


\section{Data and The Methodology}

Our data is based on the Morgan Stanley Capital International (MSCI) stock price index and the oil price index during the period January 1975 -October 2013 on weekly basis. ${ }^{1}$

The empirical investigation is based on the Granger causality test. Below we describe an asymmetric version of this test developed by Hatemi-J (2012). This test method can separate the causal effect of positive shocks from the negative ones. Allowing for asymmetric causal effects accords well with the reality, especially in financial markets, because investors tend to react more to adverse changes than favorable ones. The main advantage of this asymmetric causality test is that it totally separates the causal impact of positive changes from the negative ones, unlike alternative methods that make use of indicator variables, thresholds or regime switching methods that allow for some form of asymmetric effects within the same model. This asymmetric causality also performs well when the underlying data is not normally distributed and the volatility is time-varying. These are useful properties especially when the financial or energy related data sets are used since non-normality and time-varying volatility is usually a rule than an exception.

It is widely agreed that both oil price index (signified by $O$ ) and stock price index (represented by $S$ ) are integrated variables. Consequently, each time series can be expressed as the following:

$$
O_{t}=O_{t-1}+\varepsilon_{1 t}=O_{0}+\sum_{i=1}^{t} \varepsilon_{1 i},
$$

and

$$
S_{t}=S_{t-1}+\varepsilon_{2 t}=S_{0}+\sum_{i=1}^{t} \varepsilon_{2 i},
$$

for $t=1,2, \ldots T . O_{0}$ and $S_{0}$ are the initial value for each time series. The disturbance terms are presented by $\varepsilon_{1 i}$ and $\varepsilon_{2 i}$ and are presumed to be white noise processes. Positive and

\footnotetext{
${ }^{1}$ The number of observations is 2027.
} 
negative shocks are defined as $\varepsilon_{1 i}^{+}=\operatorname{Max}\left(\varepsilon_{1 i}, 0\right), \varepsilon_{2 i}^{+}=\operatorname{Max}\left(\varepsilon_{2 i}, 0\right), \quad \varepsilon_{1 i}^{-}=\operatorname{Min}\left(\varepsilon_{1 i}, 0\right)$ and $\varepsilon_{2 i}^{-}=\operatorname{Min}\left(\varepsilon_{2 i}, 0\right) .{ }^{2}$ Based on these definitions, we can conclude that $\varepsilon_{1 i}=\varepsilon_{1 i}^{+}+\varepsilon_{1 i}^{-}$ and $\varepsilon_{2 i}=\varepsilon_{2 i}^{+}+\varepsilon_{2 i}^{-}$. These definitions imply in turn the following: $O_{t}=O_{t-1}+\varepsilon_{1 t}=O_{0}+\sum_{i=1}^{t} \varepsilon_{1 i}^{+}+\sum_{i=1}^{t} \varepsilon_{1 i}^{-}$ and $S_{t}=S_{t-1}+\varepsilon_{2 t}=S_{0}+\sum_{i=1}^{t} \varepsilon_{2 i}^{+}+\sum_{i=1}^{t} \varepsilon_{2 i}^{-}$.

These results provide the possibility to express the cumulative positive and negative changes as $O_{t}^{+}=\sum_{i=1}^{t} \varepsilon_{1 i}^{+}, \quad O_{t}^{-}=\sum_{i=1}^{t} \varepsilon_{1 i}^{-}, S_{t}^{+}=\sum_{i=1}^{t} \varepsilon_{2 i}^{+}$and $S_{t}^{-}=\sum_{i=1}^{t} \varepsilon_{2 i}^{-}$. These components can be used for testing for asymmetric causality. For example, if the null hypothesis that positive oil shocks do not cause positive shocks in the stock prices is tested then the data vector is defined as $X_{t}^{+}=\left(S_{t}^{+}, O_{t}^{+}\right){ }^{3}$ This hypothesis can be tested via the following vector autoregressive model of order $L, \operatorname{VAR}(L):^{4}$

$$
X_{t}^{+}=v+A_{1} X_{t-1}^{+}+\mathrm{K}+A_{p} X_{t-L}^{+}+u_{t}^{+},
$$

here $v$ represents a $2 \times 1$ vector of intercepts and $u_{t}^{+}$is a $2 \times 1$ vector of error terms. The $A_{r}$ is a $2 \times 2$ matrix of coefficients for lag order $L(L=1, \ldots, L$-max $)$. The optimal lag order is chosen by minimizing the information criterion that follows

$$
\mathrm{HJC}=\ln \left(\left|\Omega_{f}\right|\right)+\frac{L}{2 T}\left(m^{2} \ln T+2 m^{2} \ln (\ln T)\right), \quad L=0, \Lambda, L-\max .
$$

where $\left|\hat{\Omega}_{j}\right|$ is the determinant of the variance-covariance matrix of $u_{t}^{+}$that is estimated by using lag order $L, m$ represents the number of the time-series in the VAR model, and $T$

\footnotetext{
${ }^{2}$ These definitions were also used by Granger and Yoon (2002) to test for hidden cointegration.

${ }^{3}$ For causality testing between negative cumulative shocks the vector $X_{t}^{-}=\left(S_{t}^{-}, O_{t}^{-}\right)$is used.

${ }^{4}$ The VAR model was originally suggested by Sims (1980).
} 
is the length of sample of the underlying data set. ${ }^{5}$ Based on the optimal lag order, the following null hypothesis can be tested: ${ }^{6}$

$H_{0}$ : the row $j$, column $k$ element in $A_{r}$ is equal to zero for $r=1, \ldots, L$.

This null hypothesis of no causality is tested via a Wald test that needs to be defined within this context. Before defining this test we need to introduce some denotations for make the presentation of the test compactly. Hence, consider the following: ${ }^{7}$

$$
\begin{aligned}
& Y:=\left(X_{1}^{+}, \Lambda, X_{T}^{+}\right) \quad(m \times T) \text { matrix, } \\
& D:=\left(v, A_{1}, \Lambda, A_{L}\right) \quad(m \times(1+m L)) \text { matrix, }
\end{aligned}
$$$$
Z_{t}:=\left[\begin{array}{c}
1 \\
y_{t}^{+} \\
y_{t-1}^{+} \\
\mathrm{M} \\
y_{t-p+1}^{+}
\end{array}\right]((1+m L) \times 1) \text { matrix, for } t=1, \ldots, T,
$$

$Z:=\left(Z_{\mathbf{0}}, \Lambda, Z_{T-\mathbf{1}}\right) \quad((1+m L) \times T)$ matrix, and

$\delta:=\left(u_{1}^{+}, \Lambda, u_{T}^{+}\right) \quad(m \times T)$ matrix.

By using these denotations we can define the $\operatorname{VAR}(L)$ model compactly as

$$
Y=D Z+\delta
$$

The following Wald test statistic can be used to test the null hypothesis of non-Granger causality, i.e. $\mathrm{H}_{0}: R B=0$,

$$
\text { Wald }=(R B)^{\prime}\left[R\left(\left(Z^{\prime} Z\right)^{-1} \otimes \Sigma_{U}\right) R^{\prime}\right]^{-1}(R B),
$$

Note that $B=\operatorname{vec}(D)$ where vec is the column-stacking operator; $\otimes$ is the tensor product, and $R$ is an $L \times m(1+m L)$ indicator matrix consisting of ones for restricted parameters and zeros for the unrestricted parameters. $\Sigma_{U}$ is the unrestricted variance-covariance matrix,

\footnotetext{
${ }^{5}$ The HJC has been suggested by Hatemi-J (2003, 2008). The conducted Monte Carlo simulations by the mentioned author have shown clearly that the $H J C$ is effective in finding the optimal lag order even when there is ARCH. This information criterion has also good forecasting capabilities based on the simulation results.

${ }^{6}$ An extra lag that is unrestricted was included in the VAR model in order to account for the effect of one unit root as suggested by Toda and Yamamoto (1995).

${ }^{7}$ The initial values are assumed to be available (see Lutkepohl; 2005).
} 
which is defined as $\Sigma_{U}=\frac{\hat{\delta}_{U}{ }^{\prime} \hat{\delta}_{U}}{T-c}$, where $c$ is the number of estimated parameters in each equation of in the underlying VAR model. Under the assumption of normality, the Wald test has a $\chi^{2}$ distribution asymptotically with $L$ degrees of freedom. However, when the data is not normally distributed and the volatility is time-varying then the small-sample distribution of this statistic is not exactly represented by the asymptotic distribution. A solution for this shortcoming is to produce critical values via bootstrap simulations with leveraged corrections. This approach can be implemented via the following steps. First, estimate the regression model (6) with the restrictions under the null hypothesis of no causality imposed. Next, generate the bootstrap data, denoted by $Y_{t}^{*}$ as $Y^{*}=\hat{D} Z+\delta^{*}$. Where $\delta^{*}$ is the bootstrapped residuals that are created by $T$ independent random draws from the regression's modified residuals. Each bootstrap sample of the bootstrapped residuals is centred in order to ensure that the necessary assumption of zero mean of the residuals is satisfied. It should be underlined that the original residuals are weighted by leverages to adjust for time-varying volatility. ${ }^{8}$ Hence, the bootstrapping relies on these modified residuals. The bootstrap simulations are repeated 10000 times. Each time the Wald is estimated. In this way the distribution of the underlying test is estimated. The critical value based on the bootstrapping at the $\alpha$-level of significance (denoted by $c_{\alpha}^{*}$ ) can be acquired by cutting the ( $\alpha$ )th upper quantile of the bootstrap distribution. Finally, the calculated the Wald statistic based on the original data can be compared to the $c_{\alpha}^{*}$ in order to decide whether or not the null hypothesis of no asymmetric causality is supported empirically. This asymmetric causality test with bootstrapping and leveraged corrections is conducted via a statistical software component that is written in Gauss by Hatemi-J (2011) and it is available online.

\footnotetext{
${ }^{8}$ Details on leverage adjustment are provided by Davison and Hinkley (1999) for univariate analysis and Hacker and Hatemi-J (2006) for multivariate analysis.
} 


\section{Empirical Results}

Before testing for causality, we implemented tests for multivariate normality and multivariate $\mathrm{ARCH}$ effects. The results, which are not reported but available upon request, showed that these assumptions are not sustained empirically. As a consequence, we need to implement bootstrap simulations with leverage adjustments in order to acquire reliable critical values that are more reliable. Since each variable contains one unit root, we also need to include an extra unrestricted lag in the VAR model in order to take into account the unit root effect following the recommendations by Toda and Yamamoto (1995). ${ }^{9}$ The empirical findings pertinent to symmetric as well as asymmetric causality tests are presented in Table 1.

\section{[Insert Table 1 Here]}

When standard symmetric causality is used there is no causation effect from oil prices on the stock prices for the world market or any G7 countries separately. However, when asymmetric causality tests are used the results show that the increasing oil prices cause the stock prices in the rising world market, the US market and the Japan market. The results also show that decreasing oil prices cause the falling stock prices in Germany only.

Thus, changes in oil prices affect the world stock market and that of the US, Japan and Germany, in the case of the G7 countries. However, only increases in oil prices impact the world, US and Japanese stock markets while only oil price decreases affect the German stock market. The world, US and Japanese stock markets respond to oil price increases and in a positive way (i.e. increase in returns). This implies that they consider oil price increases as good news as it may indicate a positive development in the world economy. These stock markets probably interpret oil price increases as being driven by demand from the economy which could therefore signal economic growth. These stock

\footnotetext{
${ }^{9}$ The unit root tests results are not presented to save space. The results are available on request however. The graphical illustrations of the variables are also in line with unit root process.
} 
markets, however, do not treat decreases in oil prices as a signal of depressed economy. The German stock market does. It responds to oil price decreases by decreasing returns. This implies that it interprets oil price decreases as bad news as it probably treats this as an indicator of a contraction in the world economy. This is a great concern for Germany given that is heavily dependent on exports.

It has been shown that the world stock markets have only generally reacted mainly to changes in oil prices caused by demand shocks rather than supply shocks (Grigoryev, 2010). This might therefore explain why the world, the US and Japanese stock market prices also increase when oil prices rise while the German stock market prices decrease when oil prices go down. These markets seem to be interpreting oil price changes as demand driven which is tied to the movement of the economy. However, the response of these markets to oil prices changes is asymmetric. The world, US and Japan respond, only to oil price increases while the Germany only to oil price decreases. To the former, oil price decreases are neither good news nor bad news while to the latter this is the case with oil price increases.

The world, the US and Japanese stock markets shrug off price decreases. It seems that they do not consider this as a factor that can significantly stimulate the economy as they may not be already so dependent on oil. Neither do they treat this as a signal of a decrease in oil demand due to a slowing economy. As regards the German stock market, it is a puzzle that it is not sensitive to increases to oil prices inspite of the fact that it is highly dependent on oil. It could probably be because Germany already uses significantly other energy sources such as nuclear, wind and solar which provides them a hedge against oil price increases. Neither does this market believe that increases in oil prices signal reduction in economic growth. Decreases in oil prices, however, affect the German equity market negatively as this could signal a downturn in the worldwide economy which is very important to them since Germany is highly export driven. 


\section{Conclusion}

This article investigated the causal impact of oil prices on each G7 well as the world stock market. An asymmetric causality test is used for this purpose. Since the underlying data appears to be non-normal with time-varying volatility, we make use of bootstrap simulations with leverage adjustments in order to produce more reliable critical values than the asymptotic ones. It is found that there is no causation effect from oil prices on the stock prices for the world market or any G7 countries separately. However, when asymmetric causality tests are used the results show that the increasing oil prices cause the stock prices in the rising world market, the US market and the Japan market. The results also show that decreasing oil prices cause the falling stock prices in Germany only. This seems to imply that the world, the US and Japanese stock markets consider increases in oil prices as an indicator of good economic news. Perhaps, this rise in oil prices is coming from an increase in demand that therefore signals future economic growth. On the other hand, the German stock market seems to be sensitive to decreases in oil prices as it may consider this as a signal of future economic contraction. Thus, it appears that the reaction of these stock markets is implying that they are reacting to a change in oil price that is demand driven which is line with the existing literature. 


\section{References}

Ajmi, A.; El-montasser, G.; Hammoudeh, S. and Nguyen, D. (2014). Oil prices and MENA stock markets: New evidence from nonlinear and asymmetric causality during and after the crisis period. Applied Economics, 46, 18 , 2167-2177.

Apergis, N., and Miller, S.M. (2009), Do structural oil - market shocks affect stock prices?, Energy Economics, 31 (4), pp. 569-575.

Arouri, M. and Nguyen, D. (2010). Oil Prices, Stock Markets and Portfolio Investment: Evidence from Sector Analysis in Europe over the Last Decade

Basher, S.A. and Sadorsky, P. (2006), Oil price risk and emerging stock market, Global Finance Journal, 17 (2), pp. 224-251.

Black, F. (1976). "Studies in Stock Price Volatility Changes", Proceedings of the 1976 Business Meeting of the Business and Economics Statistics Section, American Statistical Association, pp. 177-181.

Burbidge, J., and Harrison, A. (1984). Testing for the effects of oil-price rises using vector autoregressions. International Economic Review, 25(2), 459-484.

Campbell, J.Y. and Hentschel, L. (1992). "No News is Good News: An Asymmetric Model of Changing Volatility in Stock Returns", Journal of Financial Economics, 31, 3, pp. 281-318.

Chen, N. F., Roll, R., \& Ross, S. A. (1986). Economic forces and the stock market. Journal of Business, 383-403.

Chen, S. (2010). Do higher oil prices push the stock market into bear territory? Energy Economics, 32, 2, 490-495.

Chiang, I., Hughen, W. and Sagi, J. (2015). Estimating Oil Risk Factors Using Information from Equity and Derivatives Markets. Journal of Finance. LLX, 2, 769-804.

Christensen, J. (2011), Oil Price Shocks and Stock Returns: Empirical Evidence for the G-7 and Norway, unpublished PhD thesis, Aarhus School of Business, Aarhus University, Denmark.

Christie, A.A. (1982). "The Stochastic Behavior of Common Stock Variances: Value, Leverage and Interest Rate Effects", Journal of Financial Economics, 10, pp. 407432.

Cong, R-C., Wei, Y-M., Jiao, J-L., and Fan, Y. (2008) Relationships between oil price shocks and stock market: An empirical analysis from China, Energy Policy, vol. 36, no. 9 , pp. 3544-3553.

Davison, A.C. and Hinkley, D.V. (1999) Bootstrap Methods and Their Application, Cambridge University Press, Cambridge.

Dhaoui, A. and Khraief, N. (2014) Empirical Linkage between Oil Price and Stock Market Returns and Volatility: Evidence from International Developed Markets. Discussion Paper No. 2014-12 | March 20, 2014 | http://www.economicsejournal.org/economics/discussionpapers/2014-12

Doornik J. A. and Hansen H. (2008), “An Omnibus Test for Univariate and Multivariate Normality", Oxford Bulletin of Economics and Statistics, 70(3), 927-939.

El-Sharif, I., Brown, D., Nixon, B. and Russel, A. (2005), Evidence on the nature and extent of the relationship between oil and equity value in UK, Energy Economic, 27 (6), pp. 819-930. 
French, K.R.; Schwert, G.W. and Stambaugh, R.F. (1987). "Expected Stock Returns and Volatility", Journal of Financial Economics, 19, pp. 3-29.

Gisser, M., and Goodwin, T. H. (1986). Crude oil and the macroeconomy: Tests of some popular notions: Note. Journal of Money, Credit and Banking, 18(1), 95-103.

Grigoryev, R. (2010). The interdependence between stock markets of BRIC and developed countries and the impact of oil prices on this interdependence. $\mathrm{PhD}$ thesis. University of Portsmouth.

Güntner, J.H., (2013). How do international stock markets responds to oil demand and supply shocks?, Macroeconomic Dynamics, pp.1-26.

Hacker R. S. and Hatemi-J A. (2005), "A Multivariate Test for ARCH Effects", Applied Economics Letters, 12(7), 411-417.

Hacker R. S. and Hatemi-J A. (2006), "Tests for Causality between Integrated Variables Using Asymptotic and Bootstrap Distributions: Theory and Application”, Applied Economics, 38(13), 1489-1500.

Hacker R. S. and Hatemi-J A. (2009), "MV-ARCH: GAUSS Module to Implement the Multivariate ARCH Test," Statistical Software Components G00009, Boston College Department of Economics. Available at: http://ideas.repec.org/c/boc/bocode/g00009.html.

Hacker R. S. and Hatemi-J A. (2012) A bootstrap test for causality with endogenous lag length choice: theory and application in finance, Journal of Economic Studies, 39(2), 144-160.

Hamilton, D.J. (1983), Oil and the macroeconomy since World War II, The Journal of Political Economy, 9, pp. 228-248.

Hamilton, J.D. (2011), Nonlinearities and the macroeconomic effects of oil prices, Macroeconomic Dynamic, 15, pp. 364-378.

Hatemi-J, A. (2003) A new method to choose optimal lag order in stable and unstable VAR models, Applied Economics Letters, 10(3), 135-137.

Hatemi-J, A. (2008) Forecasting properties of a new method to choose optimal lag order in stable and unstable VAR models, Applied Economics Letters, 15(4), 239-243.

Hatemi-J A (2012) Asymmetric Causality Tests with an Application, Empirical Economics, vol. 43(1), 447-456.

Hatemi-J, A. (2011) ACTEST: GAUSS Module to Apply Asymmetric Causality Tests, Statistical Software Components, No. G00012, Boston College Department of Economics. Link: http://ideas.repec.org/c/boc/bocode/g00014.html

Hatemi-J A (2014) Asymmetric generalized impulse responses with an application in finance, Economic Modelling, vol. 36, 18-22.

Hatemi-J A. and El-Khatib Y. (2016) An extension of the asymmetric causality tests for dealing with deterministic trend components, Applied Economics, forthcoming.

Hatemi-J A. and Mustafa A. (2016) TDICPS: OCTAVE Module to Transform an Integrated Variable into Cumulative Partial Sums for Negative and Positive Components with Deterministic Trend Parts, Statistical Software Components, Nr. OCT001, Boston College Department of Economics. Available on line. (https://ideas.repec.org/c/boc/bocode/oct001.html).

Huang, R., Masulis, R., and Stoll, H. (1996). Energy shocks and financial markets. Journal of Futures Markets, 16(1), 1-27. 
Huang, R.D., Masulis, R.W. and Stoll, H.R. (1996), Energy shocks and financial markets, Journal of Future Markets, 16, pp. 1-27.

Jammazi, R. and Aloui, C. (2010) Wavelet decomposition and regime shifts: assessing the effects of crude oil shocks on stock market returns, Energy Policy, 38, 1415-35. doi:10.1016/j.enpol.2009.11.023

Jawadi, F., Arouri, M., Bellalah, M., 2010.Nonlinear linkages between oil and stock markets in developed and emerging countries. International Journal of Business 15, 19-31

Jones, C. M., and Kaul, G. (1996). Oil and the stock markets. The Journal of Finance, 51(2), 463-491.

Jones, M.C. and Kaul, G. (1996), Oil and stock markets, The Journal of Finance, 51 (2), pp. 463-491.

Kaul, G. (1987). Stock returns and inflation: The role of the monetary sector. Journal of Financial Economics, 18(2), 253-276.

Kaul, G., and Seyhun, H. N. (1990). Relative price variability, real shocks, and the stock market. The Journal of Finance, 45(2), 479-496.

Kiran, B. (2011) Fractional Cointegration Relationship Between Oil Prices And Stock Markets: An Empirical Analysis From G7 Countries, Prague Economic Papers, 2, 177-189.

Lee, B.J., Yang, C.H. and Huang, B.H. (2012), Oil price movements and stock market revisited: a case of sector stock price indexes in the G7 countries, Energy Economics, 34, pp. 1284-1300.

Lee, C. and Zeng, J. (2011). The impact of oil price shocks on stock market activities: Asymmetric effect with quantile regression, Journal of Mathematics and Computers in Simulation, 81(9), 1910-1920.

Lutkepohl H. (2005) New Introduction to Multiple Time Series Analysis. Springer.

Maghyereh, A., Al-Kandari, A., 2007.Oil prices and stock markets in GCC countries: new evidence from nonlinear cointegration analysis. Managerial Finance 33, 449460.

Naifar, N. and Al Dohaiman, M. H. (2013) Nonlinear analysis among crude oil prices, stock markets' return and macroeconomic variables, International Review of Economics \& Finance, 27, 416-31. doi:10.1016/j.iref.2013.01.001

Nandha, M. and Faff, R. (2008). Does Oil Move Equity Prices? A Global View. Energy Economics, 30, 3, 986-997.

Nandha, M. and Hammoudeh, S. (2006). "Systematic Risk, and Oil Price and Exchange Rate Sensitivities in Asia-Pacific Stock Markets", Research in International Business and Finance, 21, 2, 326-341.

Nelson, D. (1991). "Conditional Heteroskedasticity in Asset Returns: A New Approach", Econometrica, 59, pp. 347-370.

O'Neill, J.T., Penm, J. and Terrell, D.R. (2008), The role of higher oil prices: a case of major developed countries, Research in Finance, 24 (2008), pp. 287-299.

Ono, S. 2011, „Oil price shocks and stock markets in BRICse ${ }^{\text {ee }}$, The European Journal of Comparative Economics, 8(1), pp. 29-45.

Papapetrou, E. (2001), Oil price shocks, stock market, economic activity and employment in Greece, Energy Economics, 23 (5) (2001), pp. 511-532. 
Papapetrou, E. (2001). Oil price shocks, stock market, economic activity and employment in Greece. Energy Economics, 23(5), 511-532.Park, J. and Ratti, R. A. (2008) Oil price shocks and the stock markets in the U.S. and 13European countries, Energy Economics, 30(5), pp. 2587-2608.

Park, J. and Ratti, R.A. (2008), Oil prices and stock markets in the U.S. and 13 European countries, Energy Economics, 30, pp. 2587-2608.

Ramos, S. and Vega, H. (2010). Oil price asymmetric effects: Answering the puzzle in international stock markets. Energy Economics, 38, 136-145.

Reboredo, J. and Rivera-Castro, M. (2014), Wavelet-based evidence of the impact of oil prices on stock returns, International Review of Economics and Finance, 29, pp. $145-176$.

Sadorsky, P. (1999), Oil price shocks and stock market activity, Energy Economics, 21, pp. 449-469. Sadorsky, P. (2001), Risk factors in stock returns of Canadian oil and gas companies, Energy Economics, 23, pp. 17-28.

Sadorsky, P. (1999) Oil price shocks and stock market activity, Energy Economics, vol. 21 , no. 5, pp. 449-469.

Schmeling, M. (2009). Investor sentiment and stock returns: some international evidence, Journal of Empirical Finance 16, 394-408.

Schwert, G.W. (1990). "Stock Volatility and the Crash of 87", Review of Financial Studies, 3, pp. 77-102.

Sims C. (1980), Macroeconomics and Reality, Econometrica, 48 , 1-48.

Toda, H. Y. and Yamamoto, T. (1995) Statistical Inference in Vector Autoregressions with Possibly Integrated Processes, Journal of Econometrics, 66, 225-250.

Zhu, H.-M., Li, R. and Li, S. (2014) Modelling dynamic dependence between crude oil prices and Asia-Pacific stock market returns, International Review of Economics \& Finance, 29, 208-23. doi:10.1016/j.iref.2013.05.015 
Table 1 - The Symmetric and Asymmetric Causality Test Results

\begin{tabular}{|c|c|c|c|c|c|}
\hline $\begin{array}{c}\text { NULL } \\
\text { HYOTHESIS }\end{array}$ & Test Value & $\begin{array}{l}\text { Bootstrap } \\
\text { CV at } 1 \%\end{array}$ & $\begin{array}{l}\text { Bootstrap } \\
\text { CV at } 5 \%\end{array}$ & $\begin{array}{l}\text { Bootstrap } \\
\mathrm{CV} \text { at } 10 \%\end{array}$ & $\begin{array}{c}\text { Causal } \\
\text { Parameter }\end{array}$ \\
\hline \multicolumn{6}{|l|}{ World } \\
\hline$O \neq>S$ & 1.124 & 6.861 & 3.860 & 2.700 & \\
\hline$O^{+} \neq>S^{+}$ & $11.308 * *$ & 15.299 & 11.067 & 9.214 & 0.022 \\
\hline$O^{-} \neq>S^{-}$ & 4.836 & 22.448 & 16.275 & 13.645 & \\
\hline \multicolumn{6}{|l|}{ US } \\
\hline $0 \neq>S$ & 1.403 & 6.742 & 3.878 & 2.691 & \\
\hline$O^{+} \neq>S^{+}$ & $11.066 * *$ & 15.462 & 10.793 & 9.194 & 0.015 \\
\hline$O^{-} \neq>S^{-}$ & 2.235 & 18.718 & 11.919 & 9.572 & \\
\hline \multicolumn{6}{|l|}{$\mathrm{UK}$} \\
\hline$O \neq>S$ & 1.439 & 6.723 & 3.807 & 2.809 & \\
\hline$O^{+} \neq>S^{+}$ & 0.003 & 6.848 & 4.188 & 2.801 & \\
\hline$O^{-} \neq>S^{-}$ & 1.684 & 13.970 & 9.707 & 8.163 & \\
\hline \multicolumn{6}{|l|}{ France } \\
\hline$O \neq>S$ & 1.423 & 6.218 & 3.813 & 2.722 & \\
\hline$O^{+} \neq>S^{+}$ & 0.611 & 6.159 & 3.758 & 2.695 & \\
\hline$O^{-} \neq>S^{-}$ & 4.531 & 13.298 & 10.045 & 7.937 & \\
\hline \multicolumn{6}{|l|}{ Germany } \\
\hline$O \neq>S$ & 0.511 & 6.894 & 3.874 & 2.801 & \\
\hline$O^{+} \neq>S^{+}$ & 0.420 & 6.365 & 4.061 & 2.512 & \\
\hline$O^{-} \neq>S^{-}$ & $8.077 *$ & 12.929 & 9.505 & 7.758 & 0.026 \\
\hline \multicolumn{6}{|l|}{ Italy } \\
\hline$O \neq>S$ & 1.896 & 6.734 & 4.015 & 2.951 & \\
\hline$O^{+} \neq>S^{+}$ & 0.776 & 6.025 & 3.799 & 2.771 & \\
\hline \multicolumn{6}{|l|}{$O^{-} \neq>S^{-}$} \\
\hline \multicolumn{6}{|l|}{ Canada } \\
\hline$O \neq>S$ & 1.170 & 7.937 & 4.051 & 2.780 & \\
\hline$O^{+} \neq>S^{+}$ & 0.620 & 6.940 & 4.054 & 2.754 & \\
\hline$O^{-} \neq>S^{-}$ & 3.545 & 13.369 & 9.842 & 7.781 & \\
\hline \multicolumn{6}{|l|}{ Japan } \\
\hline$O \neq>S$ & 0.027 & 5.942 & 3.610 & 2.588 & \\
\hline$O^{+} \neq>S^{+}$ & $3.005^{*}$ & 6.194 & 3.561 & 2.454 & 0.025 \\
\hline$O^{-} \neq>S^{-}$ & 3.635 & 14.168 & 9.861 & 7.787 & \\
\hline
\end{tabular}

Notes:

1. $O$ denotes the oil price index and $S$ represents the stock price index. The vector $\left(S^{+}, O^{+}\right)$ signifies the cumulative positive shocks and $\left(\mathrm{S}^{-}, \mathrm{O}^{-}\right)$represents the cumulative negative shocks.

2. ** means significant at $5 \%$ level, * means significant at $10 \%$ level.

3. We tested for multivariate normality using the Doornik and Hansen (2008) statistic. The results showed that the data is not normally distributed. Tests for ARCH effects were also conducted by using Hacker and Hatemi-J (2005) bootstrap multivariate LM test. The simulations were conducted by the statistical software component provided by Hacker and Hatemi-J (2009). The results revealed that multivariate ARCH effects prevail. 